\title{
Hospital Referral Patterns: How Emergency Medical Care Is Accessed in a Disaster
}

\author{
Michael J. Reilly, DrPH, MPH, NREMT-P; David Markenson, MD, FAAP, EMT-P
}

\section{ABSTRACT}

Background: A prevalent assumption in hospital emergency preparedness planning is that patient arrival from a disaster scene will occur through a coordinated system of patient distribution based on the number of victims, capabilities of the receiving hospitals, and the nature and severity of illness or injury. In spite of the strength of the emergency medical services system, case reports in the literature and major incident after-action reports have shown that most patients who present at a health care facility after a disaster or other major emergency do not necessarily arrive via ambulance. If these reports of arrival of patients outside an organized emergency medical services system are accurate, then hospitals should be planning differently for the impact of an unorganized influx of patients on the health care system. Hospitals need to consider alternative patterns of patient referral, including the mass convergence of self-referred patients, when performing major incident planning.

Methods: We conducted a retrospective review of published studies from the past 25 years to identify reports of patient care during disasters or major emergency incidents that described the patients' method of arrival at the hospital. Using a structured mechanism, we aggregated and analyzed the data.

Results: Detailed data on 8303 patients from more than 25 years of literature were collected. Many reports suggest that only a fraction of the patients who are treated in emergency departments following disasters arrive via ambulance, particularly in the early postincident stages of an event. Our 25 years of aggregate data suggest that only $36 \%$ of disaster victims are transported to hospitals via ambulance, whereas $63 \%$ use alternate means to seek emergency medical care.

Conclusions: Hospitals should evaluate their emergency plans to consider the implications of alternate referral patterns of patients during a disaster. Additional consideration should be given to mass triage, site security, and the potential need for decontamination after a major incident.

(Disaster Med Public Health Preparedness. 2010;4:226-231)

Key Words: referral patterns, emergency departments, hospitals, disasters, emergency medical services, triage

$\mathrm{T}$ he emergency medical services (EMS) system is an effective means of delivering prehospital medical care and transporting ill or injured victims to definitive care facilities. Essential components of the prehospital response to disasters includes scene size-up and site controls, the rapid triage of victims, determination of the need for emergency decontamination, and the provision of basic medical care. ${ }^{1}$ In addition, during the EMS management of mass casualty incidents (MCIs) and routine emergencies, consideration is given to the nature and severity of injuries or illness and the capabilities of local receiving hospitals when transport decisions are made. ${ }^{1}$ Ideally, EMS attempts to transport victims to facilities that are able to accept patients and that have the appropriate specialty services to treat critically injured victims (eg, trauma, burns). ${ }^{1}$ Hospitals have come to rely upon these facets of the EMS system and expect that during a mass casualty event they will receive advance notification of the incident, and patients will be sent to receiving facilities based on the facilities' capacity and capabilities.

In disasters, however, victims' behavior is often unpredictable. Injured people seldom linger at the scene after a ter- rorist incident or major emergency for EMS to arrive, control the scene, and arrange transport to hospitals. Because scene controls and site security take time to implement, "the walking wounded" and individuals who can selfextricate will generally leave the disaster site and seek safety before the arrival of EMS. ${ }^{2-6}$ There is no reliable way to ensure that all of the victims of a disaster or act of terrorism will remain on site. Unfortunately, this may mean that some people who require urgent medical care may not receive it, victims may unknowingly be contaminated with a hazardous substance, and hospitals may be surprised by an unannounced convergence of walk-in patients after a disaster. This self-referral behavior can be a significant problem in light of reports released in the past several years that describe the lack of preparedness of hospitals, particularly as it relates to triage, mass care, and decontamination. ${ }^{6-10}$

Additional factors that can make the self-referral pattern more significant is that there are often greater numbers of people with minor illnesses and injuries after a disaster or terrorist event than there are victims with critical or life-threatening injuries. ${ }^{2-6,11-22}$ This is of particular importance because "the walking wounded" are 
more likely than a nonambulatory, critically injured person to flee a disaster scene. In addition, it is becoming apparent that people who are not physically ill or injured but insist on seeking medical care, often referred to as "the worried well," will also self-present to health care facilities. This population of patients can be large and may include members of the public who were not exposed directly to harm. ${ }^{23-25}$

Auf der Heide attempted to shed some light on a variety of disaster planning assumptions routinely used by health care emergency managers. ${ }^{6}$ Many of these assumptions are based on conventional wisdom and do not accurately reflect the actual behaviors exhibited by emergency responders, prehospital personnel, or the public during and immediately after a disaster. ${ }^{6}$ Unfortunately, not all emergency planners have discovered this work and considered it in developing their hospital emergency preparedness plans for mass casualty events. We have focused on 1 of these critical assumptions, which we believe has an important impact on hospital disaster planning.

Case reports in the literature and major incident after-action reports have shown that many people who may be ill or injured after a disaster or major incident do not necessarily arrive at emergency departments (EDs), hospitals, and trauma centers via ambulance. . $-6,11,12,15-22^{2}$ If these reports are accurate, then hospitals and emergency managers should be planning differently for a mass convergence of patients on the health care system. Such planning includes considering alternative patterns of patient presentation including self-referral and managing ill or injured victims who may be hazardous or infectious. Failure to plan accordingly may affect the ability of the health care system to respond adequately to the health and medical needs of the public after a disaster, act of terrorism, or public health emergency.

We performed a systematic review of the medical literature published in the past 25 years to identify case reports, research studies, and after-action analyses that describe the specific means that patients have used to access medical care in hospital EDs immediately after a disaster, act of terrorism, or public health emergency.

\section{METHODS}

A comprehensive medical literature database search was performed using the MEDLINE/PubMed search engines. The investigators identified reports of patient care after disasters or major emergency incidents. Reports were queried for specific information on how the patients presented to or were referred to hospitals immediately after a disaster or significant event. Final articles were selected based on their reporting of how victims were transported to medical centers and hospitals after the incident. The time frame was limited to 25 years of the published literature, 1983-2008.

Articles were identified through a targeted key word search that identified articles that appeared to contain data relevant to our investigation. Key words included but were not limited to EMS, ambulance, paramedic, MICU, hospital, emergency department, triage, disaster, terrorism, MCI, self-referred, referral patterns, and transport. Special attention was paid to articles that described after-action reports, lessons learned, and emergency medical care in a postdisaster environment. Articles were specifically reviewed to determine whether the article reported the number of patients and the method of transportation of victims to hospital EDs. Victims who were explicitly not transported, in other words, patients who died at the scene, refused care, or were treated and released by on-the-scene personnel, were excluded from the study. The authors abstracted data from each manuscript and entered it into a Microsoft Excel spreadsheet (Microsoft, Redmond, WA). Basic descriptive statistics are reported in aggregate (Table 1 ).

Data were divided into 3 categories: transported by ambulance, self-transport, and other and were placed into each category in this analysis using the following parameters:

- Ambulance: Patients entered into this category were specifically designated by the study authors as having been transported in an ambulance (air or ground) or specifically transported by emergency medical services.

- Self-transport to the hospital: Any study that indicated that patients "presented themselves," were considered "walking wounded," or used "private vehicles" was placed into this category.

- Other: This category was reserved for patients who did not ride in an ambulance (air or ground) or who explicitly did not meet the criteria for self-transport. Patients in this category arrived at hospitals mostly by bus, mass transit, or did not have the mode of transportation clearly delineated in the study but were certain to have been treated at the hospital.

\section{RESULTS}

A total of 166 reviews of disasters or major incidents were identified in the literature; $22(13.3 \%)$ reported specific data on the transportation of casualties from the scene to hospitals (Table 1). ${ }^{2-5,11-22,26-32}$ The studies included contained a heterogeneous cross-section of disasters from natural and human made to acts of terrorism (Figure 1).

The final analysis consisted of 8303 patients from 24 separate disasters or terrorist events. Nearly all of the case reports reviewed discussed the importance of the prehospital emergency care system. However, most suggest that only a fraction of the patients who are treated arrive at the ED via ambulance, particularly in the early postincident stages of a disaster. ${ }^{2-5,11,12,15-22}$ Overall, only 2980 (35.9\%) of patients involved in these 24 disasters were transported to hospitals in ambulances; 5244 $(63.2 \%)$ were transported to medical facilities via alternate means of transportation (Figure 2). Of the patients who were not transported in ambulances, $4813(91.8 \%)$ transported themselves to hospitals for medical care and $431(8.2 \%)$ sought other means of transportation to hospitals. 
The categories most clearly defined across the studies were patients who were transported in ambulances and patients who transported themselves to hospitals. There were a variety of alternative means of transport to EDs in the 24 studies. These nonambulance methods were placed into the "other" category. Some studies described these methods, such as bus or coach transportation ${ }^{5,14,15,18,21,22}$; others did not describe these methods. ${ }^{4,11,12,32}$

In general, patients who were not transported were placed into 1 of 3 categories: treated at the scene and released, died at the scene, or refused medical treatment or transportation. For the

\section{TABLE 1}

\section{Categorization of Patients From Each Study ${ }^{\mathrm{a}}$}

\section{Event}

Taba terrorist attack: suicide bombings ${ }^{15}$

San Diego firestorm ${ }^{32}$

London bombings ${ }^{18}$

African soccer stadium stampede ${ }^{17}$

Elks lodge building collapse ${ }^{11}$

Suicide bombing of Tel Aviv nightclub ${ }^{30}$

Oklahoma City bombing ${ }^{4,5}$

World Trade Center sample ${ }^{3}$

Australian bushfires 20

Volendam café fire 21

Reading, UK, train crash $^{14}$

New York City power outage $(2003)^{13}$

Turkish plane crash $^{26}$

Coal mine explosion ${ }^{27}$

Mass shooting ${ }^{28}$

Madrid train bombings ${ }^{2}$

Truck explosion ${ }^{12}$

Bus bombing ${ }^{29}$

Air show accident ${ }^{16}$

Florida hurricanes $(2004)^{19}$

Suicide bombing ${ }^{31}$

Chlorine release from train derailment ${ }^{22}$

25-Year totals
Patients, No.

200
138
194
56
50
56
388
1103
139
233
76
23
21
40
22
1180
82
58
45
3958
91
150
8303

Ambulance
$15(7.5)$
$105(76.1)$
$2(1)$
$21(37.5)$
$15(30)$
$39(69.6)$
$90(23.2)$
$282(25.6)$
$56(40.3)$
$107(45.9)$
$34(44.7)$
$13(56.5)$
$21(100)$
$40(100)$
$22(100)$
$388(32.9)$
$1(1.2)$
$55(94.8)$
$3(6.7)$
$1562(39.5)$
$57(62.6)$
$52(34.7)$
$2980(35.9)$

$$
\begin{gathered}
\text { Self-Transport } \\
20(10) \\
0(0) \\
167(86.1) \\
23(41.1) \\
14(28) \\
17(30.4) \\
179(46.1) \\
821(74.4) \\
83(59.7) \\
108(46.4) \\
0(0) \\
8(34.8) \\
0(0) \\
0(0) \\
0(0) \\
792(67.1) \\
20(24.4) \\
0(0) \\
42(93.3) \\
2396(60.5) \\
28(30.8) \\
95(63.3) \\
4813(58.0)
\end{gathered}
$$

$\begin{array}{cc}\text { Other } & \text { No Transport } \\ 133(66.5) & 32(16) \\ 18(13) & 15(10.9) \\ 25(12.9) & 0(0) \\ 0(0) & 12(21.4) \\ 16(32) & 5(10) \\ 0(0) & 0(0) \\ 119(30.7) & 0(0) \\ 0(0) & 0(0) \\ 0(0) & 0(0) \\ 18(7.7) & 0(0) \\ 36(47.4) & 6(7.9) \\ 2(8.7) & 0(0) \\ 0(0) & 0(0) \\ 0(0) & 0(0) \\ 0(0) & 0(0) \\ 0(0) & 0(0) \\ 61(74.4) & 0(0) \\ 0(0) & 3(5.2) \\ 0(0) & 0(0) \\ 0(0) & 0(0) \\ 0(0) & 6(6.6) \\ 3(2) & 0(0) \\ \mathbf{4 3 1}(5.2) & 79(1.0) \\ & \end{array}$

${ }^{a}$ Data are expressed as №. (\%).

\section{FIGURE 1}

\section{Types of disasters by category.}

\begin{tabular}{|l|l|l|}
\hline \multicolumn{1}{|c|}{ Terrorist } & \multicolumn{1}{c|}{ Natural } & \multicolumn{1}{c|}{ Man-Made Accident } \\
\hline Taba terrorist attack: Suicide bombings & San Diego firestorm & Soccer stadium stampede in Africa \\
\hline London bombings & Brushfires in Australia & Elks lodge building collapse \\
\hline Suicide bombing of Tel Aviv nightclub & Hurricane Charley & Cafe fire in Volendam \\
\hline Oklahoma City bombing - 1995 & Hurricane Frances & Train crash in Reading, UK \\
\hline World Trade Center 2001 & Hurricane Jeanne & NYC power outage 2003 \\
\hline Madrid train bombings & & Plane crash in Turkey \\
\hline Bus bombing & & Coal mine explosion \\
\hline Suicide bombing & & Mass shooting \\
\hline & & Lorry explosion \\
\hline & & Air show accident \\
\hline & & Chlorine release from train derailment \\
\hline
\end{tabular}




\section{FIGURE 2}

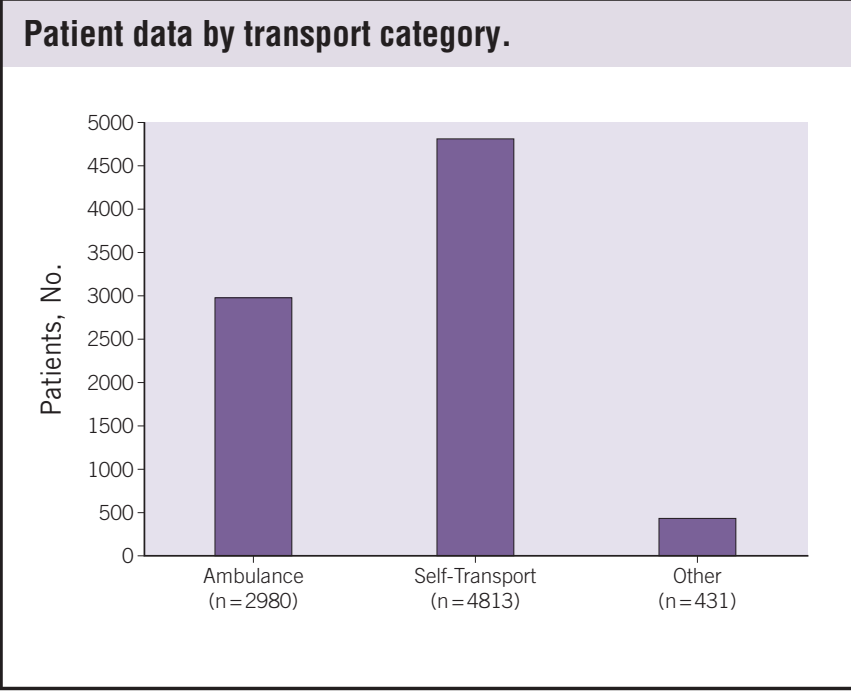

purposes of this analysis, these patients were excluded and only amounted to 79 (1\%; Table 1$)$.

\section{COMMENT}

Some assumptions are made by emergency planners about the referral patterns of patients to hospitals after a disaster, act of terrorism, or public health emergency. One assumption, as noted in previous investigations, is that if patients are acutely ill or injured, then they will arrive at hospitals, primarily by ambulance. ${ }^{6}$ Another common assumption is that when patients do arrive at hospital EDs, they will have been transported to facilities that can provide the appropriate specialty care that is needed, based on their injuries (eg, burn care, trauma care, pediatrics). ${ }^{6}$ The final assumption is that patients arriving by EMS-initiated transportation will have been appropriately triaged, decontaminated if necessary, and given medical treatment or stabilized before arrival. ${ }^{6}$ These assumptions are usually based on the perceived strength of the EMS system. ${ }^{1}$

Although during normal EMS system operations patients typically are triaged to receiving facilities based on their condition and any specialty care that they may need, during an MCI or disaster patients may need to be transported to facilities that lack certain specialty capabilities to deliver all of the victims to an acute care hospital. As a result, the hospital may need to alter its normal standard of care to meet the needs of patients with higher acuity or more complex clinical needs. In addition, patients who require decontamination may present to the ED. If a hospital is in close proximity to the incident location, then multiple patients may converge rapidly on the facility and special security and/or lockdown considerations may exist. Hospital emergency managers who are not planning for the likelihood of a mass convergence of self-referred patients from a disaster, act of terrorism, or public health emergency may be putting the safety and health of their staff, patients, and visitors in jeopardy.
In many locations, the EMS system is strong; however, our investigation has validated previous work showing that patients often disregard EMS and show up at the ED on their own. ${ }^{2-6,11,12,15-22}$ Many victims who survive these events flee the scene well before the first arriving emergency vehicles and may well be on their way to the closest medical facilities. In fact, many will have minor injuries or illnesses that do not inhibit patients who are able to self-transport to hospitals after the event. ${ }^{2-6,11-22}$ As a result, hospitals must be prepared to perform initial triage of "the walking wounded" (outside the hospital, in case of contaminated patients). In addition, facilities must have the ability to perform emergency decontamination of multiple victims, enforce tight perimeter security, including lockout or lockdown procedures when necessary, and create an area for "the worried well" and people with minor injuries to be cared for while awaiting the potential arrival of more critically injured or ill victims from the scene. ${ }^{6}$

In addition to the implications for hospital emergency planners, this study also has implications for incident command personnel at the scene of an event. Although scene controls, such as establishing a perimeter, delineating hot/warm/cold zones, estimating numbers of victims, and assigning kinds and types of resources, take time to be put in place, many ambulatory patients will leave the scene. The self-extrication of "walking wounded" victims may pose special challenges. It may be more difficult to first estimate the true number of victims from an event, when many may be actively leaving the scene. "Walking wounded" patients may be contaminated or infectious and may spread illness or cause secondary exposure to other people or locations. Mass dispersal of victims with minor illnesses or injuries may result in the loss of forensic evidence or make witness interviews after a criminal or terrorist event difficult. Epidemiologic investigations may also be affected by limiting the tracking of cases and ability to perform case and contact tracing. All of these reasons are important to emphasize scene security and perimeter controls as soon as possible when responding to a major incident.

There were several limitations to this study. First, our literature review initially returned 166 articles; however, only 22 reported complete data that were useable for analysis of this research question (Table 1 ). One reason for this low number of included studies is the underwhelming number of published case reports or after-action reports in the peer reviewed literature that reported, in sufficient detail, how victims arrived at hospitals after the event. A second reason was that many articles discussed transportation of casualties to hospitals, but they did not provide quantifiable data to report in this study. In addition, we purposely excluded articles published in non-English-language journals, which may have contributed to lower numbers for our analysis. Because these articles were not read for inclusion, it is impossible to estimate how many of them would have been appropriate for inclusion in this review. To remedy this in future analyses, we suggest that future investigators of emer- 
gency care and treatment of casualties postdisaster report data on how patients arrived at hospitals, trauma centers, and EDs. This may help provide a more accurate picture of the ways in which patients access emergency care after a disaster.

Second, the scope of our literature review was somewhat narrow-only 25 years retrospectively using only the PubMed/ MEDLINE database. Because not all after-action reports appear in the medical peer-reviewed literature, the Lessons Learned Information System database operated by the Department of Homeland Security was also consulted, but it contained mainly executive summaries of incidents without actual numbers and dispositions of casualties. With such few investigators reporting useable data, this time frame may have been too short to yield enough data to generalize to all types of disasters. Future studies should look at longer time periods and multiple search engines to gather a more representative sample.

Third, because cases in which victims were transported by bus to hospitals for treatment were placed in the "other" category, we did not have enough information to determine whether this meant that patients chose to take buses to hospitals or whether EMS personnel arranged for ambulatory or "walking wounded" patients to ride in chartered buses for the purposes of mass transportation to medical centers. If this were part of the local EMS response, then these patients would have been triaged and possibly treated on the scene by prehospital personnel and hospitals notified of their impending arrival. Even if we assumed that all of the patients in the "other" category were EMS-initiated transports, then it would still result in only $40 \%$ of the disaster victims arriving via ambulance. This result would not change our interpretation of the results of our study; more victims of disasters who choose to seek immediate medical attention will arrive at hospitals through self-transport than via EMS or ambulance transportation.

Fourth, because it is, in general, easy to quantify the number of patients transported in ambulances to hospitals through EMS call logs and data available in patient care reports, there is no mechanism for reliable quantification of patients who selfrefer to medical treatment after disasters. This is of particular concern when victims seek treatment at clinics, urgent care centers, or their primary care physicians and not hospitals. This may have resulted in an underreporting of patients in the self-transport category, biasing our results in favor of EMS-initiated transport mechanisms to hospitals and medical centers.

\section{CONCLUSIONS}

Our study suggests that after a disaster, act of terrorism, or public health emergency, victims most often present to hospitals and EDs through self-referral rather than via ambulance transportation, validating previous work in this area. The implications for hospitals should include the development of emergency procedures and preparedness plans that address the complications associated with a mass influx of walk-in or self-referred patients after a disaster. Emergency procedures and preparedness plans should include staff's proficiency in triage, ability to perform emergency decontamination, and safety and security procedures should they encounter a patient surge at their facility. Future studies should attempt to report how victims reach emergency care in disasters so that we may better understand referral patterns after mass casualty events.

Author Affiliations: Dr Reilly is assistant director and Dr Markenson is director, Center for Disaster Medicine, New York Medical College.

Correspondence: Address correspondence and reprint requests to Dr Michael J. Reilly, Center for Disaster Medicine, New York Medical College, SPH Bldg, 3rd Floor, Valhalla, NY 10595 (e-mail: michael_reilly@nymc.edu).

Received for publication August 7, 2008; accepted August 16, 2010.

Author Disclosures: The authors report no conflicts of interest.

Acknowledgment: The authors thank Julia Mathew for assistance with performing literature reviews in the preparation of this article.

\section{REFERENCES}

1. Bledsoe B, Porter R, Cherry R. Essentials of Paramedic Care. Upper Saddle River, NJ: Prentice Hall; 2003.

2. Carresi AL. The 2004 Madrid train bombings: an analysis of pre-hospital management. Disasters. 2008;32(1):41-65.

3. Centers for Disease Control and Prevention (CDC). Rapid assessment of injuries among survivors of the terrorist attack on the World Trade CenterNew York City, September 2001. MMWR Morb Mortal Wkly Rep. 2002; $51(1): 1-5$.

4. Hogan DE, Waeckerle JF, Dire DJ, Lillibridge SR. Emergency department impact of the Oklahoma City terrorist bombing. Ann Emerg Med. 1999;34(2):160-167.

5. Teague DC. Mass casualties in the Oklahoma City bombing. Clin Orthop Relat Res. 2004;(422):77-81.

6. Auf der Heide E. The importance of evidence-based disaster planning. Ann Emerg Med. 2006;47(1):34-49.

7. Health Resources and Services Administration. A 2002 National Assessment of State Trauma System Development, Emergency Medical Services Resources, and Disaster Readiness for Mass Casualty Events. Washington, DC: HRSA; 2003.

8. Reilly M, Markenson DS. Education and training of hospital workers: who are essential personnel during a disaster? Prehosp Disaster Med. 2009; 24(3):239-245.

9. US General Accounting Office. Hospital Preparedness: Most Urban Hospitals Have Emergency Plans but Lack Certain Capacities for Bioterrorism. Washington, DC: GAO; 2003.

10. Institute of Medicine Committee on the Future of Emergency Care in the United States Health System. Hospital-Based Emergency Care: At the Breaking Point. Washington, DC: National Academies Press; 2007.

11. Casey R, Christy J, Ellis D, Wade J. Elks Lodge building collapse. Emerg Med Serv. 2006;35(12):185-188, 193.

12. Evans GW, Isgar B, Bruins W, Glover JR. The Peterborough lorry explosion, 22 March 1989: an analysis of the hospital response. Arch Emerg Med. 1990;7(4):253-258.

13. Greenwald PW, Rutherford AF, Green RA, Giglio J. Emergency department visits for home medical device failure during the 2003 North America blackout. Acad Emerg Med. 2004;11(7):786-789.

14. Howells NR, Dunne N, Reddy S. The casualty profile from the Reading train crash, November 2004: proposals for improved major incident reporting and the application of trauma scoring systems. Emerg Med J. 2006; 23(7):530-533.

15. Karp E, Sebbag G, Peiser J, et al. Mass casualty incident after the Taba 
terrorist attack: an organisational and medical challenge. Disasters. 2007; 31(1):104-112.

16. Kossmann T, Wittling I, Bühren V, Sutter G, Trentz O. Transferred triage to a level I trauma center in a mass catastrophe of patients; many of them with burns. Acta Chir Plast. 1991;33(3):145-150.

17. Madzimbamuto FD. A hospital response to a soccer stadium stampede in Zimbabwe. Emerg Med J. 2003;20(6):556-559.

18. Mohammed AB, Mann HA, Nawabi DH, Goodier DW, Ang SC. Impact of London's terrorist attacks on a major trauma center in London. Prehosp Disaster Med. 2006;21(5):340-344.

19. Platz E, Cooper HP, Silvestri S, Siebert CF. The impact of a series of hurricanes on the visits to two central Florida Emergency Departments. J Emerg Med. 2007;33(1):39-46.

20. Richardson DB, Kumar S. Emergency response to the Canberra bushfires. Med J Aust. 2004;181(1):40-42.

21. van Harten SM, Welling L, Perez RS, Patka P, Kreis RW. Management of multiple burn casualties from the Volendam disaster in the emergency departments of general hospitals. Eur J Emerg Med. 2005;12(6):270-274.

22. Wenck MA, Van Sickle D, Drociuk D, et al. Rapid assessment of exposure to chlorine released from a train derailment and resulting health impact. Public Health Rep. 2007;122(6):784-792.

23. Dallas CE. Detonation of a nuclear device. In: Keys DC, Burstein JL, Schwartz RB, Swienton RE, eds. Medical Response to Terrorism: Preparedness and Clinical Practice. Philadelphia: Lippincott Williams \& Wilkins; 2005:180.

24. Lacy TL, Benedek DM. Psychological impact of terrorist incidents. In: Roy MJ, ed. Physician's Guide to Terrorist Attack. Totowa, NJ: Humana Press; 2004:379-390.
25. Socher MM, Leap EK. Training preparedness for terrorism. In: Keys DC, Burstein JL, Schwartz RB, Swienton RE, eds. Medical Response to Terrorism: Preparedness and Clinical Practice. Philadelphia: Lippincott Williams \& Wilkins; 2005:338.

26. Ağalar F, Cakmakçi M, Er M, Akçakanat A, Sayek I. Evaluation of trauma care in a developing country highlighted by a major aircraft accident. Eur J Emerg Med. 1997;4(2):97-102.

27. Allister C, Hamilton GM. Cardowan coal mine explosion: experience of a mass burns incident. Br Med J (Clin Res Ed). 1983;287(6389):403405.

28. Beyersdorf SR, Nania JN, Luna GK. Community medical response to the Fairchild mass casualty event. Am J Surg. 1996;171(5):467-470.

29. Katz E, Ofek B, Adler J, Abramowitz HB, Krausz MM. Primary blast injury after a bomb explosion in a civilian bus. Ann Surg. 1989;209(4): 484-488.

30. Leiba A, Halpern P, Priel IE, et al. A terrorist suicide bombing at a nightclub in Tel Aviv: Analyzing response to a nighttime, weekend, multicasualty incident. J Emerg Nurs. 2006;32(4):294-298.

31. Raiter Y, Farfel A, Lehavi O, et al. Mass casualty incident management, triage, injury distribution of casualties and rate of arrival of casualties at the hospitals: lessons from a suicide bomber attack in downtown Tel Aviv. Emerg Med J. 2008;25(4):225-229.

32. Vilke GM, Smith AM, Stepanski BM, Ray LU, Murrin PA, Chan TC. Impact of the San Diego county firestorm on emergency medical services. Prehosp Disaster Med. 2006;21(5):353-358. 